\title{
The principles of Vastu as a traditional architectural belief system from an environmental perspective
}

\author{
H. Fazeli \& A. Goodarzi \\ Department of Architecture, University of Malaya, Malaysia
}

\begin{abstract}
The shortage of technological discoveries in traditional architecture - which has now made it possible to warm and cool any area regardless of considering the proper direction or geometrical shape - used to lead the habitants to make use of natural phenomena to provide physical and emotional comfort. Therefore, traditional architecture is always accompanied with a set of rules and principles that are to some extent based on environmental criteria as well as the dominant belief system of the specific culture; these two variables seem to be inter-related and in some situations dominating one another. Although assigning auspicious directions, auspicious geometrical patterns in the plan configuration, the concept of concentric zones, elongation of the whole complex and the façade considerations seem to be religious in basis or due to cultural values, still a great amount of such principles in traditional architectural guidelines are derived from the environment; thus a number of common characteristics of vernacular architecture, such as the presence of vegetation in the buildings' site, the use of local materials that create a micro-climate adaptable with human comfort and structural forms associated with the climatic positions, which can also be applied to other cultures with the same climate, are present as parts of all traditional structures.

Vastu as one of the most ancient architectural belief systems, similar to other traditional architectural sciences such as Feng Shui, also deals with the principles designed to make the most use of the environment and more specifically climate as one of its dominant factors. Based on the knowledge of the Sun Rays, the Earth's Magnetic Poles and the Geopathic Zones, many rules have been legislated in ancient Indian architecture dealing with environmental criteria that
\end{abstract}


are now considered superstitions; however, applying them may be useful in designing buildings in complete harmony with the surrounding nature.

Keywords: principles of Vastu Shastra, the sun rays, magnetic zones, Geopathic Zones, concentric squares, the surrounding environment.

\section{Introduction}

Based on the chronic approach to the history of architecture, the patterns of primitive constructions were the inspiration of the natural forms and features. Therefore the surrounding environment has always imposed certain shapes and geometries to architectural constructions from the ancient times until the modern era. In contrast to such an approach, the followers of the cultural approach believe that the forms and patterns of traditional dwellings were the consequence of religious beliefs and the faith on sacred realms. However the architectural efforts of traditional societies are in fact the result of considering many factors, including both environment and religion, often called by the French word, 'genre de vie' signifying all the matters of shelter, material, technology, site, defence, economy and religion.

Basically environment as the first manifestations of shelter has always played a significant role in the process of man's evolution. Technology of construction as well as the geometrical patterns and sacred symbols are all derived from nature and its dominant laws. The laws of nature are basically beyond the physical tangible forces that used to constitute the principles of classical physics and contain all the intangible energy fields emitted from the earth as well as the other heavenly bodies, such as the Sun and the moon. The principles of ancient sciences of architecture including Vastu Shastra and Feng Shui denote the great knowledge of ancient civilizations over the universe, its orders and its analogy to the human body, which seems to be the sum experiences of traditional societies over generations. Therefore, along with the cultural considerations, a great number of principles in ancient architectural design were a response to the surrounding environment.

\section{Two distinctive aspects of traditional architecture}

Basically there are two different aspects of architecture as high and low. First concerns the cosmic rules to define proportion, geometry and ritual acts as representation of the universal principles in domestic art. Association of earth to vault of the sky, vertical axis and the symbolic forms of space are all manifestations of the high aspect. The latter on the other hand deals with the climatic issues, the use of materials, technologies and construction methods. While the cosmic aspect is achieved by the prolonged esoteric studies, the low scheme depends on the sum experience of generations [1]. In fact, traditional architecture is shaped in connection with culture while culture is largely dependent on the environmental context as well as cultural beliefs; along with the importance of the belief in supernatural powers and interpretations of the cosmos in forming the traditional architecture of every nation, the physical 
conditions and economical criteria as well as its relations to the land and the structural crisis which the dwellings are based on are also fundamental. In this way culture will shape due to four variables of space, time, meaning and communication as means to define the cultural activities and the ways of performing them not only in space but also in time. Based on these four variables, the same set of space organizations and architectural configurations may be found in different cultures with different climatic criteria. Thus comparing traditional domestic architecture in various cultures, one must consider the system of activities take place in dwellings rather than focusing on the individuals [2]. Based on this theory, despite having different environmental background, the traditional buildings of different cultures may still share some similar concepts.

Concerning the low aspect, a number of common characteristics of vernacular architecture can be the presence of environmental context in which they are raised, the use of local materials which creates a micro-climate adaptable with human comfort and structural forms associated with the climatic positions which can also be applied to other cultures with the same climate. Furthermore, the economical status of each culture and its habitants used to suggest the size of the house, its properties and decorations. In fact traditional architecture was completely dependent on the social and economical situations in the low aspect, and was basically developed to provide some specific requirements within each cultural environment [3].

However, no environmental factor is more important in the development of human life and culture, than climate. "The practical limits of human existence are largely defined by physical and psychological tolerance to extremes of heat or cold, while the effects of climate upon the distribution of vegetation have direct bearings on life support." [3 p. 125].

It seems that combining the climatic factors with the dominant beliefs of each community which defines its culture, may provide the characteristics of its traditional built space. Therefore the face of the buildings rarely changes through the time unless the dominant culture changes in a profound level either environmental or ideological [4]. In fact the environmental criteria in proposing certain shapes and configurations to architectural efforts of traditional societies is completely inter-related to the cultural beliefs and is proper to think that nature is the context from which all the sacred forms and symbols have been derived and transferred to next generations through a set of rules and principles of architectural design. The existance of such knowldege in the sacred scriptures of India and more specifically the Vedas reveals the importance of environmental considerations of dwelling construction for the ancient civilizations which beyond symbolical interpretation, need a scientific observation.

\section{Vastu Shastra as a traditional architectural science}

Ancient sciences of architecture are basically a combination of rules and rituals being applied by the master builders or the local craftsmen. Although these rules were applied in almost every traditional culture which is also evident in their 
ritual behaviour and folklore literature, there are few written architectural guidelines remained today which Vastu Shastra is one of them [3]. The main concept of Vastu Shastra knowledge of architecture was to guide people to create spaces which harmonize with nature and with the universal forces. The use of Vastu which is rooted in Hinduism philosophy dates back to the Vedic period appeared between 4000 and 2000 B.C. A section of Yajur Veda called 'Sthapatha Vidya' which means the art of building, mainly deals with the principles of architecture and housing. In fact there are nearly 32 books written on the subject of Vastu from 3000 B.C. to 600 A.D. by various authors in Sanskrit language dealing with the construction methods, special placements of the house features and the rituals to be done in each stage $[5,6]$.

Vastu in its general sense means the place where living beings dwell while in Rig Veda it has been applied for home. Originally Vastu is derived from the Sanskrit word, 'vas', meaning to reside [7]. However, in 'Samarangana Sutradhara' the origin of Vastu is defined as 'Vasu' or 'the earth' so that the mother earth and all the creations above it are called Vastu. Literally Vastu is applied to both the site of the building, and the building itself. Hence selection of the site, architecture, landscape and the science of the structures as well as astrology are all components of Vastu science [8].

Vastu as a traditional guide to architecture aims to design buildings in harmony with the natural laws of the universe. "As Einstein Proved, everything in existence, sentient and non-sentient, is a field of energy. In this case 'Vastu' is referred to pure subtle energy that underlies everything while 'Vaastu' is the manifestation or expression of that energy as matter" [9 p. 141]. In fact, Vastu is a science of working with energy fields which used to guide the architects to design buildings in a way that their underlying energy fields are beneficially manipulated due to proportion and direction. Thus Vastu views the dwelling places as living entities that nourish our lives, rather than a 'machine for living.' In this science, home is a symbol of physical body which is interrelated with the universal energy field and at the same time a microcosm of its existence [10].

According to Rig Veda, architecture of the ancient times was closely associated with religion, and building a structure was recognized as a religious act. Basically it was not religious in origin but since Vastu similar to Yoga and Ayurveda, denotes the connection between the laws and processes that governs the world of nature and the laws which govern the human body, it has been perceived as religious for the ancient societies. Therefore its principles should not be interpreted as mythic superstitions, rather based on laws of nature and the surrounding environment [11].

\section{The environmental principles of Vastu Shastra}

The environment as the first manifestations of shelter has been the subject of many rules and principles of Vastu science of architecture. Its presence in the spatial configurations of the plan, its geometry and directions, besides the arrangements of water pools and vegetation around the building construction is highly evident through Vastu guidelines. 
The first geometrical pattern applied as the floor plan is usually a mandala from which the rest of the concepts and patterns will be originated. The symbolic patterns and geometries of mandalas are environmental in origin and picture the natural phenomena and their influence in built space [12].

From the environmental features which suggest the shape and spatial arrangements of the patterns in the mandala, the Sun Rays, the Magnetic Poles, the Geopathic Zones and the Concentric Zones are the most significant of all which together has dictated certain principles of architectural construction.

For example the concept of the eight directions of Vastu Shastra science and their associated deities, from which the four cardinal directions are the most important, is in fact based on the climatic features of each direction. The Vastu Scientists has perceived the effects of each direction in the human system over centuries and found out that proper orientation with the cardinal directions aligns the built space with the energy grid of the earth and brings harmonious benefits. It also allows the house to absorb energies emitted from the sun, moon, stars and the earth itself properly. Further they have observed that energy is poured forth from the centre and the outer space to the inside through the directional lines which are called 'Yonis' or 'life lines' in Vastu. That's why in Vastu the building should be built in alignment with the four cardinal directions [10].

In fact the categorization of each direction as either auspicious or destructive in Vastu is based on the following concepts:

\subsection{The principles of sun-rays}

Sun rises from the east, passes through the south and sets in the west. However due to the $23.5^{\circ}$ inclination of the earth from its vertical axis, the east is not the first direction that receives the sun rays; it is northeast. The same application can be applied to the cardinal west. Hence if we draw an imaginary line from northeast to southwest, the southern half will be the light zone with positive energy while the northern half is the dark zone with negative energy. In this case the southeast which is in the middle of the light zone will have the natural light throughout the day and is recommended for the kitchen [8].

Sun ray consists of visible white light together with invisible infrared and ultraviolet rays. Approximately from 6 am the effect of infrared rays starts which is beneficial to the human health and has purifying effects. Hence water present at east, north or northeast becomes bacteriologically safe without deterioration of the ingredients. From 11 am to $3 \mathrm{pm}$ the effect of ultraviolet rays will be very high which is harmful for the body. From 3 pm until the sunset the effect of infrared rays in heat quality will increase [13]. That's why in Vastu guidelines it is advisable to located the water pool in north, northeast or east directions as an auspicious for placing the entrance door and openings while the southwest is often suggested to be kept heavy and closed [14].

Morning rays of the sun are naturally cool. Gradually the rays become hotter. Sun is in its hottest mood during the afternoon hours while passing through the southwest. By drawing an imaginary line from northwest to southeast, the hot and cold zones can be pointed. Thus the sector points are the best places for activities requiring balanced heat. Northeast in the middle of the cold zone is 
appropriate for the praying or studying while the southwest as the hottest and most destructive corner should be kept closed. In ancient times southwest was reserved as armoury to keep weapons [8].

Based on the position of the Sun in the sky during the day time, the coolest location in the house is north direction. Hence the rooms with higher priority and importance are placed in the north direction. Cow shed and paddy storage is placed in the northwest while the treasuries are kept in the north location. Library also can be a proper function for the north direction. Daily Meditations or prayer activities are done in the northeast portion, as it is the coolest corner.

East offers the morning sun which is pleasant. In modern Vastu, bathroom is placed in this direction and near the entrance hall. However in ancient times bathroom was not even included in the house planning. As southeast provides enough light throughout the day which has a sanitary effect, kitchen is the most proper function to be placed in this corner.

The light and heat of the sun in the southern portion is excessive and destructive, thus bedrooms should be placed in this direction. While bedrooms are mostly used during the night the harmful rays flowing from this direction will not disturb the habitats. This portion should be kept high, dark and closed [12].

Western portion of the house also receives the negative sunrays in a lesser degree during the day. Thus it is a better place for dining room, while only a few hours in a day will be set for dining activities.

Table 1: Spatial organization of dwelling areas based on the position of the sun.

\begin{tabular}{|c|c|c|c|c|c|c|c|c|}
\hline East & Southeast & South & South west & West & $\begin{array}{c}\text { North } \\
\text { west }\end{array}$ & North & Northeast & Centre \\
\hline $\begin{array}{c}\text { Entrance } \\
\text { Hall }\end{array}$ & Kitchen & Bedroom & $\begin{array}{c}\text { Master } \\
\text { Bedroom or } \\
\text { Storage }\end{array}$ & $\begin{array}{c}\text { Dining } \\
\text { Room }\end{array}$ & Cattle & $\begin{array}{c}\text { Treasury } \\
\text { Storage }\end{array}$ & $\begin{array}{c}\text { Meditation } \\
\text { Room }\end{array}$ & $\begin{array}{c}\text { Central } \\
\text { Courtyard }\end{array}$ \\
\hline
\end{tabular}

In this way every function in the dwelling area used to have a suggested spatial organization in the Vastu Purusha mandala which was decided through having the knowledge of the Sun Rays and their influences on the human health.

\subsection{The principles of magnetic poles}

"When a magnetic needle is suspended freely, free from any outer influence, it ends rest along north-south direction of the earth's magnetic field," which proves the existence of magnetic energy field of the earth." [8 p. 27].

Basically the earth is composed of a metallic inner core in the same size as the Moon. The temperature of this metallic core is equal to the temperature of the Sun's surface and this heat in fact causes churning in the liquid outer core of the Earth. Based on the magnetic dynamo theory, the rotation of the Earth which transforms into a whirlpool of liquid, swirling around the Earth's axis, converts the planet into a geo-dynamo. Such materials that are capable of conducting 
electricity are called metallic that have some free to move electrical charge. One of the elements in this liquid layer is compressed hydrogen which is in a state where some of its electrons are squeezed out of the atoms and are free to move around. This moving charge will generate a magnetic field and the faster the planet rotates, the stronger the produced magnetic field. Therefore the planet earth has a strong magnetic field due its fast spinning rate and material composition of its liquid core which is more iron and nickel [15].

In fact earth has two magnetic poles which based on the compass seem to be steady; whereas in reality they are constantly moving. Ephemeral undulations, known as micro-pulsations, ripple about the ionosphere and produce magnetic disturbances capable of reaching the ground level which are common and at the same time hard to detect. The Earth's magnetic field which is also called the Earth's aura in fact protects the life of its occupants from the radiations of the Sun by deflecting the solar flares.

The north magnetic pole is near the south geographical direction while the south magnetic pole is near the north geographical direction. The force lines of this magnetic field travel from the north magnetic pole to the south magnetic pole. Scientifically this will provide the north geographical direction with antibiotic properties which can control infection. Thus north direction is served as the purifying direction while the south direction, has energy giving properties which can be manifested as warmth. Therefore, while the northern half of the plot is full of positive magnetic rays, the southern part will be empty or depleted. The manifestation of such phenomenon used to decide the auspiciousness of the directions and their appropriate function in Vastu Shastra guidelines [8].

In fact, cosmic energy is abundantly received in the northeast direction and directed towards the southwest. Therefore the cosmic energy will become weaker while flowing towards southwest. Northeast will be the positive terminal and southwest as the negative one. Hence the shape of the building is crucial in the energy flow pattern [9].

Based on Vastu guidelines, the northeast section of any property should be built lighter and in a lower level compared to the southwest section to receive the beneficial effects of magnetism in its highest level and to facilitate the smooth flow of mahnetic waves without any hindrance. Furthermore it is believed in Vastu that the slope of the plot should face north or east which again is designed to make use of such natural forces. However lack of enough knowledge in studying Vastu guidelines has ended in treating the concepts of auspiciousness as merely superstitious or religious beliefs.

In fact the Earth behaves similar to a living organism and seems to have the intelligent of its own. Based on biological discoveries, the oxygen level of the planet has virtually remained unchaged through the centuries and the tilting of the Earth through the northeast direction has helped it to receive the maximum amount of beneficial cosmic energies. Aligning any built structure to the axis of the Earth will generate similar effects; therefore the northeastern half of the plot will be full of fresh beneficial cosmic radiations while the southwestern section will be empty [8]. 


\subsection{The principles of Geopathic Zones}

Geo biology is a branch of modern science deals with the various energy fields. It often falls under the category of pseudoscience and operates through geometrical patterns which are the subjects of sacred geometry. The cosmic energies are emitted from heavenly bodies such as the Sun and the Moon; whereas, these radiations are called 'telluric radiations' and are originated from the Earth. The energy grid of the planet earth can be perceived as a web that links the Earth altogether and is influenced by many variables such as electricity, magnetism, heat, sound, light, colour and matter.

The Earth's energy grid works through specific geometrical patterns which follow certain symmetries. The grids meet at many intersecting points creating a matrix which is very similar to acupuncture points of the human energy body. It is believed that the platonic solids including cube, tetrahedron, octahedron, dodecahedron and icosahedrons are the evolved geometrical patterns derived from the study of the Earth's geometrical grids [16].

Doctor Manfred Curry first hypothesized the existence of a grid network of energetic pathways flowing from northeast to southwest and from southeast to northwest at a distance of $3 \mathrm{~m}$ to $3.5 \mathrm{~m}$. This Bio Electro Magnetic (BEM) grid is sometimes called the first global diagonals which is helpful to the growth of cells. The crossing points of these lines have double positive or negative effects that can be harmful for the balance of the body. Dr Curry later linked these points with diseases and found out that sleeping on negatively charged points will cause inflammatory diseases while sleeping on positively charged points will cause cancer; thus, to remain healthy one should sleep within the grids.

Later, Dr. Hartmann discovered another pathway of energy flowing from north to south and east to west. These lines are called Hartmann lines with the spacing of 2 to $2.5 \mathrm{~m}$ that are essential for the formation of bones in the human body. Hartmann grid is basically the BEM grid in the cardinal directions. The Hartmann grid has been known in Chinese geomancy as Yin and Yang; while the Yin or north-south lines generates a cold energy field which acts slowly and is associated with cramps, humidity and all forms of rheumatism, the Yang or eastwest lines produces a hot energy field that acts rapidly and is associated with fire and all inflammatory diseases. These lines are also dangerous for the human health. By compiling the two grids in Vastu Shastra system, the square of neutral habitation zone will be produced [8].

In fact the researches has proved that, ancient civilizations were aware of such planetary grids and used to consider these energy fields during construction. For example, in the Himalayas the houses of Buddhist monks are oriented due to the $\mathrm{BEM}$ grids to be placed in the neutral zone.

Besides Curry and Hartmann lines, geopathic stress can also cause imbalance of energy field. Buildings with ill energy effects are called 'sick building syndrome' today. Day describes 'sick building syndrome' as a common disease due to the improper use of materials and designing methods in today architecture which can be reduced by reapplying the principles of vernacular houses. Sick building syndrome which is now so common and well recognized, continues to 
be developed in high rise buildings, "over-glazed and under-day lit" places which extremely use the synthetic materials causing the electromagnetic confusion. Their detachment from nature has made these buildings energy dependent and unhealthy. Thus the awareness of how buildings can attach to nature and remain in harmony with it seems to be substantial for human health as well as the energy reduction. This syndrome in general includes "headaches, irritability, hyperkinesias, learning disability, fatigue, dermatitis, asthma, rhinitis, flu mimic conditions, and irritations of the bronchia, mucous membranes, throat and eyes which are all easily mistaken for normal ill-health." [1 p. 309].

In fact negative energy exists as a cloud which can move into the building; "stress clouds are examples of the negatively charged locked energy fields." [8 p. 37]. Basically and due to the science of subtle energy, negative and positive energies flow like water. They can be created due to various reasons such as death of a person, and can flow or trapped according to the structural forms and figures. "Some of the symptoms of such negative cloud formations are palpitation or increase in the pulse rate, home ants and termites, beehives, dampness, coldness or hotness of a specific floor area, cats frequenting the house, uncommon accidents in the rooms or dogs barking at night while looking at south or southwest without any visible reason. These stress clouds affect one's Bio Electro Magnetic level, which has a great influence on his aura or energy body." [8 p. 38].

The rules and principles of Vastu applied while in the construction of any property proves the existance of such knowledge in traditional societies which might not be completely discovered by scientists yet.

\subsection{The principles of concentric zones}

While square is known as a proper shape for building, pattern of concentric squares in Vastu Purusha mandala is an archetypal pattern which establishes a potent, energetic and healthy effect based on the ancient teachings. This pattern which is found in many cultures such as Egypt, America, Europe and Asia and in works of many famous architects and artists is fundamentally composed of concentric squares which infinitely recede to the unseen centre of the universe from which all the creation emerge. Pagodas and Step Pyramids are the examples of this pattern in architecture [10].

In Indian traditional geomancy, one is the symbol of the creator or God, the infinite reality or the absolute unity which is shown by point in geometrical expression. Bindu in the centre of the Vastu Purusha mandala which indicates the navel is the manifestation of this sacred concept. Two, apart from its quantitative application, is the symbol of duality in creation which is represented by yin-yang symbol in Chinese Feng Shui. Duality of Shiva and Shakti or the male and female forces is symbolized by line in geometrical realm and is known as the source of creation of the physical world. Three on the other hand is symbolized by triangle and is called the mother which signifies the process of creation from the two abstract geometrical shapes to the triangle which is a 


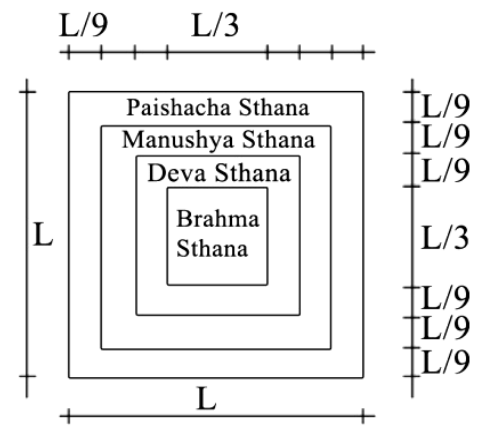

Figure 1: $\quad$ The concentric zones [8].

complete geometrical pattern. While three is the connecting link between the sacred realm and the built form, four is the symbol of created objects and represents 'the first born thing' [17]. Therefore square or rectangle were always used in designing the plan of every dwelling to represent the world of materialization or the realm of mundane which man is living on while the ceiling was considered the realm of the divine which man should ascent to [8]. The same concept is also indicated by Lao Tzu as the concept of creation which should also occur while constructing a new dwelling since it is the inferior example of the world's creation. "The Tao gives birth to one. One gives birth to two. Two gives birth to three. Three gives birth to all things." [18 pp. 10,11].

Apart from the symbolic significance, based on the studies of Kumar, square is the best geometrical shape in economical and structural considerations followed by rectangle since it requires the lesser amount of construction materials on its periphery while providing the broader inner area compared to other geometrical figures. In structural terms, "square- and rectangular-shaped buildings can transfer the load safely even where the bearing capacity of soil is low, while other irregular shapes provide large contact areas more than they critically required." [ 8 p. 41]. The symmetrical shape of rectangular figures also creates a predictable behaviour in terms of structural calculations and constructional methods which involve tortional behaviour problems and stress concentrations. Therefore symmetrical structures can perform better under the earthquake or wind forces.

Above all, based on the Vedic teachings, the geometry of square is in complete harmony with human proportions as illustrated by Leonardo da Vinci since human can fit harmoniously inside both square and circle [19].

In fact the 'concentric squares' is another symbolic diagram which was applied by Vastu Shastra specialists from ancient times in constructing their dwellings. In this diagram four belts of energy field can be recognized; the centre part is the Brahma Pada which is a highly charged zone called the 'hot zone.' Around the centre is the 'luminous space' or Deivika Pada while the third belt is called Manusha Pada or 'conscious space'. The outermost area is the 'gross material space' or Paisachika Pada. The two innermost areas are the zones which should be open or constructed with minimum walls or heavy items while the two 
outer belts are the place of human habitation and physical structure. The reason is that the energy of the two inner zones is substantially subtle for the human body [10]. However Ashvini Kumar believes that the most inner area together with the most outer area is not suitable for human living. Comparing the Vastu Purusha mandala with the human body, these two areas symbolize the nose and skin from which the body can breathe. Thus these two areas should be open and filled with windows to serve the similar function.

The idea is to treat the plan the same way as the human body. While the central parts and organs are delicate and sensitive the minimum pressure should be applied to them [8]. This idea can be seen in the development of the courtyard houses of Japan, china and Iran. The idea of concentric zones later in 1920 was suggested by American geographer E.W. Burgess as the proper plan for developing the cities [20].

\section{Conclusion}

In fact there are many principles in the Vastu Shastra science of architecture that are basically designed regarding the environmental features which through the lack of knowledge have considered symbolic or ritualistic by the later generations. However the observation of natural phenomena by the ancient philosophers leading to the discovery of laws of nature and their impact on human health is the root cause of the application of the principles of Vastu and its similar systems of beliefs in other cultures as the sum knowledge, experienced by many generations.

Since it is highly believed that the architectural forms have been proposed by the environment and as a response to its orders, which share similar patterns in regions with similar climatic configurations, the rules and principles of Vastu Shastra can be discovered and applied not merely as a superstitious symbolic guideline, rather as a proper example of using the architectural forms in the context of the environment. Although the technological advancements of today make it possible to warm and cool any area regardless of its climate, the proper use of architectural forms and patterns may lead to sustainable design which decreases the rate of energy consumption as well as making a proper micro climate compatible with human needs which can also stand in complete harmony with the surrounding environment.

\section{References}

[1] Day, Christopher. Places of the Soul: Architecture and Environmental Design as a Healing Art. s.l. : Architectural Press, 2004.

[2] Kent, Susan. Domestic Architecture and the Use of Space: An Interdisciplinary Cross-Cultural Study. s.1. : Cambridge University Press, 1993.

[3] Olivier, Paul. Encyclopedia of Vernacular Architecture of the World. s.l. : Cambridge University Press, 1997. 
[4] Gray, John N. Domestic mandala: architecture of lifeworlds in Nepal. s.1. : Ashgate Publishing, Ltd., , 2006.

[5] Hari, A. R. Amazing science of vaastu. s.l. : A.R.Hari, 2000.

[6] Bhattacharya, Trapada. A Study on Vastuvidya or Canons of Indian Architecture. s.1. : The United PRR Patna, 1974.

[7] Devi Vasudev, Gayatri and Dash, Nilakanth. Vāstu, Astrology, and Architecture: Papers Presented at the First All India Symposium on Vāstu, Bangalore, Held on June 3-4, 1995. s.1. : Motilal Banarsidass Publication, 1998.

[8] Kumar, Ashwini. Vaastu: The Art And Science Of Living: The Art and Sciene of Living. s.l. : Sterling Publishers Pvt. Ltd, 2005.

[9] Krishna, Talavane. The Vaastu Workbook: Using the Subtle Energies of the Indian Art of Placement to Enhance Health, Prosperity, and Happiness in Your Home. s.l. : Inner Traditions , 2001.

[10] Silverman, Sherri. Vastu: Transcendental Home Design in Harmony with Nature. s.1. : Gibbs Smith, 2007.

[11] Sahasrabudhe, Gautami. Cosmic Science of Vaastu. s.l. : Sterling Publishers Pvt. Ltd, 2005.

[12] Vastu Shastra and Its Importance in Residential Buildings. Akola, T. 2000. Department of Civil Engineering. p. 45.

[13] Vastu Facts. Rality in Vastu. [Online] 2009. [Cited: 5 5, 2009.] http://www.vaasthufacts.com/rlty.htm.

[14] Oldenberg, Hermann. The Grihya Sutras. Sacred Texts. [Online] 1886. [Cited: 7 2, 2009.] http://www.sacred-texts.com/hin/sbe29/sbe29131.htm.

[15] Strobel, Nick. Earth Magnetic Filed. Astronomy Notes. [Online] 9 24, 2008. [Cited: 11 24, 2009.] www.astronomynotes.com.

[16] Bachler, Käthe and Living, John M. Earth Radiation. s.l. : Holistic Intuition Society, 2007. 0968632351/9780968632352.

[17] Lawlor, Robert. Sacred Geometry: Philosophy and Practice. s.1. : Thames and Hudson, 2002.

[18] Levitt, Susan. Taoist Feng Shui. s.l. : Inner Traditions / Bear \& Company, 2000 .

[19] Marc, Olivier. Psychology of the House. s.1. : Thames \& Hudson, 1975.

[20] R. Pitzl, Gerald. Encyclopedia of human geography. s.l. : Greenwood Publishing Group, 2004. 